\title{
Evaluation of indigenous the nucleopolyhedrovirus (NPV) of Spodoptera litura (Fabricius) (Lepidoptera: Noctuidae) in combination with chlorantraniliprole against Spodoptera species
}

\author{
Ghulam Sarwar', Naeem Arshad Maan², Muhammad Ahsin Ayub³, Muhammad Rafiq Shahid',
}

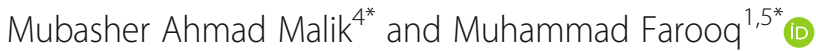

\begin{abstract}
Background: The armyworms, Spodoptera exigua (Hübner), and S. litura (Fabricius) (Lepidoptera: Noctuidae) are polyphagous pests of many cash crops. Heavy crop losses have been reported for the fruit and vegetable crops each year owing to the diverse impact on global economies. The present study was aimed to sort out a novel method of pest control using the insect's own nucleopolyhedrosis virus (NPV) alone and in combination with a new chemistry insecticide chlorantraniliprole.

Results: In the study, the effect of indigenous isolated nucleopolyhedrovirus (NPV) and the chemical insecticide (chlorantraniliprole) formulations against the 2 nd and 4 th larval instars of S. litura and S. exigua, collected from the different geographical region of Punjab (Pakistan) province, was evaluated. Three concentrations of the NPV isolate, sub-lethal $\left(1 \times 10^{4}, 6 \times 10^{4} \mathrm{POB} \mathrm{ml} l^{-1}\right)$, lethal $\left(3 \times 10^{5} \mathrm{POB} \mathrm{ml} l^{-1}\right)$, and chlorantraniliprole $0.01 \mathrm{Il}^{-1}$, were applied alone and in combination against the 2 nd and 4 th larval instars of both pest species. The lethal concentration of NPV + chlorantraniliprole exhibited synergistic interaction and caused high larval mortality against both instars, while in all other combinations, additive effect was observed. Moreover, NPV + chlorantraniliprole at lethal concentration exhibited decreased pupation, adult emergence, and egg eclosion.
\end{abstract}

Conclusion: The implications of using NPV alone and in combination with an insecticide are discussed briefly in this study.

Keywords: Nucleopolyhedrovirus, Chlorantraniliprole, Spodoptera exigua, S. litura, Combined effect

\section{Background}

Spodoptera exigua (Hübner) and S. litura (Fabricius) (Lepidoptera: Noctuidae) are native to Asia (Farahani et al. 2012). Both attack more than 90 plant species

\footnotetext{
*Correspondence: ahmadmubasher49@gmail.com;

Muhammad.farooq@hdr.qut.edu.au

${ }^{4}$ Department of Entomology, University of Agriculture, Faisalabad, Pakistan ${ }^{1}$ Cotton Research Station, Ayub Agricultural Research Institute, Faisalabad, Pakistan

Full list of author information is available at the end of the article
}

including major crops such as sugar beet, cotton, soybean, and potatoes (Fu et al. 2017; Luna-Espino et al. 2018). The mechanism of resistance in S. exigua has been reported against different classes of insecticides (Ishtiaq et al. 2012). Furthermore, extensive use of synthetic insecticides has resulted in enormous environmental pollution and a negative impact on non-target insect species (Ahmad et al. 2008). This situation forced the researchers to develop eco-friendly alternatives 
(Sayyed et al. 2012). Baculoviruses consist of rod-shaped, dsDNA-occluded viruses that infect insect pests belonging to the orders Lepidoptera, Hymenoptera, and Diptera (Williams et al. 2017). Due to their fast-killing nature and host specificity, some of these viruses have been used as commercial bioinsecticides (Sosa-Gómez 2017). Baculoviruses comprise two genera, granuloviruses (GVs) and nucleopolyhedroviruses (NPVs). The S. litura multiple nucleopolyhedroviruses (SIM-NPV) have been molecularly characterized, and their biological activity has been tested against $S$. litura populations in Pakistan (Ahmad et al. 2018; Ali et al. 2018; Ayyub et al. 2019) and all over the world (Laarif et al. 2011 and Kumar et al. 2012a, 2012b).

Chlorantraniliprole is a Ryanoid class insecticide (anthranilic diamide), which demonstrates maximum mortality against the target insect pests even at a low application rate (Cordova et al. 2007). Furthermore, this insecticide is compatible to use with NPV to enhance the pathogenic efficacy. Ryanodine receptors are ion channels that maintain calcium levels in the sarcoplasmic reticulum of muscle cells. Chlorantraniliprole opens the ryanodine receptor for an uncontrolled release of calcium from muscle cells, which reduces feeding, paralysis, and ultimately death of target species (Lahm et al. 2007). Previous studies represent the efficacy of NPVs of specific regions, but until now, no published data is available on the effect of a local isolate of NPV against Spodoptera species when applied in combination with chlorantraniliprole. Therefore, the present study was conducted to evaluate the effect of the local isolate of $S$. litura NPV alone and in combination with chlorantraniliprole against Spodoptera spp.

\section{Methods}

\section{Rearing of insects}

About 150 larvae (3rd and 4th instars) each of S. litura and $S$. exigua were collected by plucking the infested leaves from the field during the winter cropping season of 2018-2019 to establish insect cultures. The larvae along with the leaves were carried in plastic jars and shifted to the rearing cages in the laboratory with the help of a camel hairbrush. Pest species were identified based on the morphological characters traced with the help of a taxonomic key. The larvae were mass-reared on artificial diets at $25 \pm 2{ }^{\circ} \mathrm{C}, 70 \pm 5 \% \mathrm{RH}$ and a photoperiod of 14:10 h (L:D). The standard established laboratory protocol was followed (Ahmad et al. 2020) The larvae were pupated in vials containing the artificial diet. The emerged adults (approximately 120 males and females) were shifted from vials to plastic cages/boxes for mating and egg-laying purposes. The adults were provided with $10 \%$ honey solution in cages. After hatching, the neonate larvae were shifted to vials containing the artificial diet until pupation. The $F_{1}$ generation of reared test insects was mass cultured and used in bioassay experiments.

Chlorantraniliprole is a new insecticide with a novel mode of action. The semi-viscous formulation of it is provided byDuPont ${ }^{\mathrm{tm}}$ Operations Private Limited, Pakistan, containing 20\% W/V active ingredient Rynaxpyr $(200 \mathrm{ml} / \mathrm{l})$, and $80 \%$ other ingredients $(800 \mathrm{ml} / \mathrm{l})$ was used for bioassays. The formulation was applied by dissolving in distilled water at a concentration of $0.01 \mu \mathrm{l}^{-1}$ mixed with the diet, thoroughly mixed in an electric shaker for $30 \mathrm{~s}$.

\section{Viral isolation and suspension preparation}

NPV-infected larvae were macerated, and obtained polyhedral (occlusion bodies) were passed through the cheesecloth to remove large debris. Semi purified occlusion bodies were centrifuged at $3000 \mathrm{rpm}$ for $45 \mathrm{~min}$. For further purification of the occlusion bodies, the resulting suspension was centrifuged at a high speed (16, $000 \mathrm{rpm}$ ) for $10 \mathrm{~min}$. The suspension was transferred to glass vials and stored at $4{ }^{\circ} \mathrm{C}$. The concentrations of polyhedral occlusion bodies (POBs) as a stock solution $\left(2 \times 10^{8} \mathrm{POB}^{-1}, 3 \times 10^{8} \mathrm{POB}^{-1}\right.$, and $\left.4 \times 10^{8} \mathrm{POB}^{-1}\right)$ were prepared from indigenous NPV using Neubauer hemocytometer (Shapiro et al. 2005). From the stock solution, $1 \mathrm{ml}$ suspension from each concentration was prepared as NPV-1 $\left(1 \times 10^{6} \mathrm{POB} \mathrm{ml}^{-1}\right)$, NPV-2 $\left(1 \times 10^{7}\right.$ POB ml $\left.{ }^{-1}\right)$, and NPV3 $\left(4 \times 10^{8} \mathrm{POB} \mathrm{ml} l^{-1}\right)$. For bioassay, 2 sub-lethal concentrations of NPV $\left(1 \times 10^{4} ; 6 \times 10^{4}\right)$ and one lethal concentration of NPV $\left(3 \times 10^{5} \mathrm{POB}\right.$ $\mathrm{ml}^{-1}$ ) were used to study the synergistic, additive, or antagonism effect against Spodoptera species (these sublethal concentrations were selected from a preliminary bioassay).

\section{Insect bioassay}

The 2nd and 4th larval instars of S. litura and S. exigua were tested by NPV and chlorantraniliprole alone and in combination. The desired concentration of NPV from the stock solution was mixed in the artificial diet for even distribution. All the bioassays were conducted under Biosafety Level 2 to avoid any source of contamination or leakage of the pathogens. The experiments were conducted in a plastic vial (base radius of $2.4 \mathrm{~cm} \times$ height $6 \mathrm{~cm})$. Sub-lethal concentrations of NPV-1 $(1 \times$ $\left.10^{4} \mathrm{POB} / \mathrm{larva}\right)$ and NPV-2 $\left(6 \times 10^{4} \mathrm{POB} /\right.$ larva $)$ and lethal concentration of NPV-3 $\left(3 \times 10^{5} \mathrm{POB} /\right.$ larva $)$ were used to calculate the percentage mortality, pupation, adult emergence, and egg eclosion from the 2nd and 4th larval instars of S. litura and S. exigua. Each plastic vial contained a 2-mm cube of diet previously soaked in respective NPV and chlorantraniliprole concentration. Twenty pre-starved $(24 \mathrm{~h})$ larvae of both instars of $S$. 
litura and S. exigua were allowed to feed the artificial diet until complete consumption in the individual container. After being fed, the larvae were removed and then released in plastic vials containing an artificial diet until the larvae died or pupated. The bioassay was conducted at $25 \pm 2{ }^{\circ} \mathrm{C}, 70 \pm 5 \% \mathrm{RH}$ and L16:D8 h photoperiod. Each treatment was replicated 3 times, and each bioassay was repeated thrice independently. The number of dead insects was recorded daily, and surviving insects were monitored for \% pupation and adult emergence. Larvae were considered dead when they were unable to move (Ma et al. 2008). Emerged adults from each treatment were shifted from vials to plastic cages/boxes for mating and egg-laying purposes.

\section{Statistical analysis}

The mortality rate of targeted insects was corrected using Abbott's formula (Abbott 1925). The co-toxicity factor (CTF), observed mortality (Oc), and expected mortality $(\mathrm{Oe})$ were calculated using the equation (Mansour et al. 1966) $\mathrm{CTF}=(\mathrm{Oc}-\mathrm{Oe}) / \mathrm{Oe} \times 100$ to study the synergistic (cytotoxicity factor above 20), additive (cytotoxicity factor between 20 and - 20), and antagonistic (cytotoxicity factor -20 or above) interaction between the treatments. The means were compared by using the Tukey-Kramer HSD test at $P=0.05$ (Sokal and Rohlf 1995).

\section{Results}

\section{Mortality of S. litura}

The 2nd instar larvae showed a $38.10 \%$ mortality rate when exposed to a sub-lethal concentration of chlorantraniliprole $(0.01 \mathrm{ppm})$, while the larvae treated with NPV (sub-lethal $1 \times 10^{4}$, sub-lethal $6 \times 10^{4} \mathrm{POB} \mathrm{ml}{ }^{-1}$, and lethal $3 \times 10^{5} \mathrm{POB} \mathrm{m}{ }^{-1}$ ) showed 34.02, 48.41, and
$60.48 \%$ mortality, respectively. A combination of the lethal concentration of NPV $\left(3 \times 10^{5} \mathrm{POB} \mathrm{ml}{ }^{-1}\right)$ with a sub-lethal concentration of chlorantraniliprole $(0.01$ $\mathrm{ppm})$ showed a synergistic action $(\mathrm{CTF} \geq 20)$ with a mortality of $89.35 \%$, while the rest of the combination exhibited an independent effect (CTF $\leq 20)$ (Table 1). Similarly, integration of a sub-lethal + lethal combination of NPV on the 4th instar larvae showed the highest level of mortality in the 4th instar larvae than the chlorantraniliprole alone treatment. The combined treatment of NPV + chlorantraniliprole interaction produced an antagonistic or additive effect while combing chlorantraniliprole with NPV at $3 \times 10^{5} \mathrm{POB} \mathrm{ml}{ }^{-1}$ showed a mortality rate of $75.70 \pm 1.76 \%$ (Table 1 ).

\section{Mortality of S. exigua}

Sub-lethal effect of chlorantraniliprole (0.01 ppm) against the 2nd instar larvae showed 33.66\% mortality rate, whereas three concentrations of NPV (sub-lethal 1 $\times 10^{4}$, sub-lethal $6 \times 10^{2} \mathrm{POB} \mathrm{ml} \mathrm{m}^{-1}$, and lethal $3 \times 10^{5}$ POB ml ${ }^{-1}$ ) produced $30.48,42.70$, and $54.92 \%$ mortality, respectively. Simultaneous action of NPV $\left(3 \times 10^{5} \mathrm{POB}\right.$ $\mathrm{ml}^{-1}$ ) with a sub-lethal concentration of chlorantraniliprole $(0.01 \mathrm{ppm})$ showed a synergistic action $(\mathrm{CTF} \geq 20)$ with a mortality of $84.02 \%$, while the rest of the combination exhibited an independent effect of each other $(\mathrm{CTF} \leq 20)$ (Table 2). Similarly, the integration of a sublethal + lethal combination of NPV on the 4th instar larvae showed the highest level of mortality in the 4th instar larvae than the chlorantraniliprole alone treatment. In the combined treatment of NPV + chlorantraniliprole, 2 interactions produced an additive effect, while combining chlorantraniliprole with NPV at $3 \times 10^{5} \mathrm{POB} \mathrm{ml} \mathrm{m}^{-1}$ caused enhanced mortality of $57.30 \%$ (Table 2 ).

Table 1 Mortality percentage of the 2nd and 4th instars of Spodoptera litura larvae treated with nucleopolyhedrovirus alone and in combination with chlorantraniliprole

\begin{tabular}{|c|c|c|c|c|c|c|c|c|}
\hline \multirow{2}{*}{$\begin{array}{l}\text { Treatments } \\
\left(\text { POB } \mathrm{ml}^{-1}\right)\end{array}$} & \multicolumn{4}{|c|}{ 2nd instar larvae $(n=20)$} & \multicolumn{4}{|c|}{ 4th instar larvae $(n=20)$} \\
\hline & Mortality\% & Expected mortality & CTF & Interaction & Mortality \% & Expected mortality & CTF & Interaction \\
\hline NPV-1 $\left(1 \times 10^{4}\right)$ & 34.02 & & & & 20.43 & & & \\
\hline NPV-2 $\left(6 \times 10^{4}\right)$ & 48.41 & & & & 32.69 & & & \\
\hline NPV-3 $\left(3 \times 10^{5}\right)$ & 60.48 & & & & 42.29 & & & \\
\hline Chl & 38.10 & & & & 24.43 & & & \\
\hline NPV-1+Chl & 74.13 & 75.58 & -6.63 & Additive & 42.52 & 43.61 & -0.85 & Additive \\
\hline NPV-2+Chl & 85.56 & 75.67 & 14.54 & Additive & 55.53 & 54.17 & 12.14 & Additive \\
\hline $\mathrm{Npv}-3+\mathrm{Chl}$ & 89.35 & 79.42 & 20.16 & Synergistic & 75.70 & 65.91 & 19.13 & Synergistic \\
\hline Control & 2.38 & & & & 1.59 & & & \\
\hline$F$ & 251 & & & & 275 & & & \\
\hline DF & 7,71 & & & & 7,62 & & & \\
\hline$P$ & $<0.01$ & & & & $<0.01$ & & & \\
\hline
\end{tabular}

CFT co-toxicity factor 
Table 2 Mortality percentage of the 2nd and 4th instars of Spodoptera exigua larvae treated with nucleopolyhedrovirus alone and in combination with chlorantraniliprole

\begin{tabular}{|c|c|c|c|c|c|c|c|c|}
\hline \multirow{2}{*}{$\begin{array}{l}\text { Treatments } \\
\left(\text { POB } \mathrm{ml}^{-1}\right)\end{array}$} & \multicolumn{4}{|c|}{ 2nd instar larvae $(n=20)$} & \multicolumn{4}{|c|}{ 4th instar larvae $(n=20)$} \\
\hline & Mortality\% & Expected mortality & CTF & Interaction & Mortality \% & Expected mortality & CTF & Interaction \\
\hline NPV-1 $\left(1 \times 10^{4}\right)$ & 30.48 & & & & 15.89 & & & \\
\hline$N P V-2\left(6 \times 10^{4}\right)$ & 42.70 & & & & 25.51 & & & \\
\hline NPV-3 $\left(3 \times 10^{5}\right)$ & 54.92 & & & & 38.68 & & & \\
\hline Chl & 33.66 & & & & 20.56 & & & \\
\hline NPV-1+Chl & 65.90 & 60.25 & 1.78 & Additive & 37.59 & 31.12 & 10.14 & Additive \\
\hline NPV-2+Chl & 71.53 & 68.24 & 3.74 & Additive & 46.67 & 38.31 & 17.21 & Additive \\
\hline $\mathrm{Npv}-3+\mathrm{Chl}$ & 84.02 & 70.13 & 26.22 & Synergistic & 57.30 & 45.12 & 21.57 & Synergistic \\
\hline Control & 3.17 & & & & 3.18 & & & \\
\hline$F$ & 271 & & & & 117 & & & \\
\hline DF & 7,71 & & & & 7,62 & & & \\
\hline$P$ & $<0.01$ & & & & $<0.01$ & & & \\
\hline
\end{tabular}

CFT co-toxicity factor

\section{Pupation percentage of S. litura}

A significant interaction was found between NPV and chlorantraniliprole in terms of the number of larvae that enter the pupation stage (2nd instar $F 7,71=257, p \leq$ 0.01 , 4th instar $F 7,71=319, p \leq 0.01)$. The integration effect of both agents was lethal as compared to their sole applications. The combined lethal concentration of NPV with chlorantraniliprole against the 2nd and 4th larval instars of $S$. litura produced synergistic interaction with a decreasing percentage of pupation (3.11 and 4.15\%, respectively). In contrast, the highest percentage of pupation (40.67 and $36.26 \%$, respectively) was observed at a low concentration of chlorantraniliprole (Table 3).

\section{Pupation percentage of S. exigua}

Among treatment of NPV and chlorantraniliprole, the interaction was significant for pupation percentage (2nd instar $F 7,71=221, p \leq 0.01$, 4th instar $F 7,71=342, p \leq$ 0.01). The lethal combination effect of NPV with chlorantraniliprole was synergistic with a high rate of mortality in the 2nd and 4th larval instars of S. exigua and a low percentage of pupation, while the rest of the combinations of lethal concentration of NPV with chlorantraniliprole produced synergistic interaction with decreasing percentages of pupation (5.33 and $12.307 \%$, respectively). On the other hand, a low concentration of chlorantraniliprole produced the highest percentage of pupation (51.89 and 41.22\%, respectively) (Table 4).

Adult emergence and egg eclosion percentage of S. litura Adult emergence rate was inversely proportional to all the treatments of NPV and chlorantraniliprole (Table 3). The lowest adult emergence (8.22 and 1.00\%) and egg eclosion (2.94 and 4.32\%) were observed when a high

Table 3 The mean pupation, adult emergence, and egg eclosion ( $\% \pm$ SE) of the 2 nd and 4th instars $(n=20)$ of Spodoptera litura larvae treated with nucleopolyhedrovirus alone and in combination with chlorantraniliprole

\begin{tabular}{|c|c|c|c|c|c|c|}
\hline \multirow{2}{*}{$\begin{array}{l}\text { Treatments } \\
\left(\text { POB ml }{ }^{-1}\right)\end{array}$} & \multicolumn{2}{|l|}{ Pupation } & \multicolumn{2}{|c|}{ Adult emergence } & \multicolumn{2}{|l|}{ Egg eclosion } \\
\hline & 2nd instar & 4th instar & 2nd instar & 4th instar & 2nd instar & 4th instar \\
\hline$\overline{N P V-1}\left(1 \times 10^{4}\right)$ & $71.81 \pm 2.22$ & $74.63 \pm 2.23$ & $71.11 \pm 2.73$ & $64.44 \pm 1.93$ & $67.21 \pm 2.70$ & $76.63 \pm 3.12$ \\
\hline$N P V-2\left(6 \times 10^{4}\right)$ & $61.01 \pm 2.57$ & $65.81 \pm 1.93$ & $60.15 \pm 2.74$ & $52.96 \pm 2.11$ & $54.99 \pm 3.84$ & $65.65 \pm 3.10$ \\
\hline NPV-3 $\left(3 \times 10^{5}\right)$ & $54.67 \pm 1.47$ & $50.52 \pm 2.18$ & $50.00 \pm 1.96$ & $48.52 \pm 1.97$ & $42.38 \pm 2.69$ & $49.33 \pm 2.61$ \\
\hline Chl & $40.67 \pm 2.05$ & $36.26 \pm 2.14$ & $47.78 \pm 2.51$ & $31.85 \pm 2.83$ & $35.00 \pm 3.45$ & $38.04 \pm 3.91$ \\
\hline NPV-1+Chl & $25.15 \pm 2.41$ & $24.44 \pm 1.27$ & $47.41 \pm 1.77$ & $22.16 \pm 1.19$ & $24.93 \pm 2.58$ & $29.29 \pm 2.56$ \\
\hline NPV-2+Chl & $2.63 \pm 2.18$ & $13.67 \pm 2.11$ & $27.96 \pm 2.55$ & $6.30 \pm 2.63$ & $11.37 \pm 3.62$ & $18.54 \pm 3.76$ \\
\hline NPV-3+Chl & $03.11 \pm 0.00$ & $4.15 \pm 1.87$ & $8.22 \pm 1.58$ & $01.00 \pm 0.10$ & $2.94 \pm 2.35$ & $4.32 \pm 2.38$ \\
\hline Control & $96.41 \pm 2.98$ & $97.5 \pm 2.37$ & $94.85 \pm 2.15$ & $95.07 \pm 1.34$ & $87.37 \pm 4.63$ & $92.74 \pm 4.02$ \\
\hline$F$ & 257 & 319 & 291 & 366 & 44 & 53 \\
\hline Df & 7,71 & 7,71 & 7,71 & 7,71 & 7,71 & 7,71 \\
\hline$P$ & $<0.01$ & $<0.01$ & $<0.01$ & $<0.01$ & $<0.01$ & $<0.01$ \\
\hline
\end{tabular}


Table 4 The mean pupation, adult emergence, and egg eclosion ( $\% \pm$ SE) of the 2 nd and 4 th instars $(n=20)$ of Spodoptera exigua larvae treated with nucleopolyhedrovirus alone and in combination with chlorantraniliprole

\begin{tabular}{|c|c|c|c|c|c|c|}
\hline \multirow{2}{*}{$\begin{array}{l}\text { Treatments } \\
\left(\text { POB } \mathrm{ml}^{-1}\right)\end{array}$} & \multicolumn{2}{|l|}{ Pupation } & \multicolumn{2}{|c|}{ Adult emergence } & \multicolumn{2}{|l|}{ Egg eclosion } \\
\hline & 2nd instar & 4th instar & 2nd instar & 4th instar & 2nd instar & 4th instar \\
\hline NPV-1 $\left(1 \times 10^{4}\right)$ & $82.52 \pm 1.43$ & $78.59 \pm 2.58$ & $69.89 \pm 1.75$ & $79.26 \pm 1.88$ & $74.94 \pm 3.40$ & $87.23 \pm 5.55$ \\
\hline$N P V-2\left(6 \times 10^{4}\right)$ & $72.70 \pm 1.14$ & $71.30 \pm 2.54$ & $64.44 \pm 2.65$ & $75.56 \pm 2.12$ & $62.72 \pm 2.60$ & $77.54 \pm 4.25$ \\
\hline NPV-3 $\left(3 \times 10^{5}\right)$ & $60.44 \pm 1.59$ & $65.52 \pm 2.14$ & $52.22 \pm 3.14$ & $65.93 \pm 2.17$ & $49.53 \pm 3.17$ & $58.08 \pm 3.99$ \\
\hline Chl & $51.89 \pm 2.45$ & $41.22 \pm 1.93$ & $44.07 \pm 1.17$ & $51.74 \pm 2.38$ & $40.68 \pm 5.26$ & $49.29 \pm 5.07$ \\
\hline NPV-1+Chl & $30.37 \pm 0.00$ & $34.07 \pm 2.24$ & $36.67 \pm 3.06$ & $50.37 \pm 1.91$ & $33.38 \pm 2.17$ & $42.14 \pm 2.98$ \\
\hline NPV-2+Chl & $21.59 \pm 1.85$ & $20.56 \pm 1.48$ & $12.00 \pm 2.66$ & $32.44 \pm 1.82$ & $20.99 \pm 2.10$ & $25.07 \pm 4.88$ \\
\hline NPV-3+Chl & $5.33 \pm 1.37$ & $12.30 \pm 3.17$ & $4.15 \pm 2.74$ & $17.59 \pm 1.54$ & $5.50 \pm 1.23$ & $9.55 \pm 2.26$ \\
\hline Control & $97.29 \pm 2.58$ & $96.63 \pm 2.65$ & $95.56 \pm 1.12$ & $96.69 \pm 2.65$ & $90.63 \pm 2.71$ & $93.89 \pm 8.56$ \\
\hline$F$ & 221 & 342 & 168 & 219 & 36 & 26 \\
\hline Df & 7,71 & 7,71 & 7,70 & 7,71 & 7,71 & 7,71 \\
\hline$P$ & $<0.01$ & $<0.01$ & $<0.01$ & $<0.01$ & $<0.01$ & $<0.01$ \\
\hline
\end{tabular}

concentration of NPV $\left(3 \times 10^{5}\right)$ was combined with chlorantraniliprole against the 2nd and 4th larval instars, respectively. Adult emergence and egg eclosion rates were high at the sole application of chlorantraniliprole. The combined application of microbes produced fatal effects on adult emergence and egg eclosion as compared to their sole application.

\section{Adult emergence and egg eclosion percentage of $S$. exigua}

The relationship between adult emergence rate and bioassay treatment was inversely proportion (Table 4). The percentage of adult emergence (4.15 and $17.59 \%)$ and egg eclosion (5.50 and 9.55\%) of the 2nd and 4th larval instars, respectively, were the lowest when a lethal concentration of NPV $\left(3 \times 10^{5} \mathrm{POB} \mathrm{ml} \mathrm{m}^{-1}\right)$ was combined with chlorantraniliprole. Sole application of both agents produced a high percentage of adult emergence and egg eclosion. The integration effect of biorational insecticides was toxic for adult emergence and egg eclosion than that of their sole application.

\section{Discussion}

The practical use of microbial insecticides is limited due to host specificity and slow in action. Combing biorational insecticides with microbes is a premixing strategy to manage insecticide overuse (Kumar et al. 2012a, 2012b). Biological insecticides have been used to control lepidopteran insect pests of agricultural, horticultural, and forest importance (Nathan and Kalaivani 2006).

A molecularly identified isolate of NPVs has been used to control Spodoptera spp. in Pakistan (Ahmad et al. 2018; Ali et al. 2018) and worldwide (Luna-Espino et al. 2018). In the present study, after the viral infection, Spodoptera spp. showed stunted growth and prolonged larval and pupal duration. Insect pests of vegetable, ornamental, and field crops have been shown more vulnerability to the pathogenicity of NPV infection (RiosVelasco et al. 2011). Early instar larvae were more succumb to pathogenic infection than older larvae because early ones usually consumed more surface of viral treated leaves (Gothama et al. 1995). It is likely due to more deposition of cuticular melanism in the oldest larvae which prevents the entrance of pathogens (Wilson et al. 2001).

Chlorantraniliprole is a novel insecticide (Cordova et al. 2006). In the present study, it showed a good control against both larval instars of Spodoptera spp., but the 2nd instar larvae showed high susceptibility. Low concentrations of chlorantraniliprole gave fair control against lepidopteron insect pests (Cordova et al. 2006; Wakil et al. 2013; Wang et al. 2013). Synergistic interaction was produced in the present study when a high concentration of NPV was combined with chlorantraniliprole. Similar synergistic interaction was reported by Wakil et al. (2012) for Bacillus thuringiensis + chlorantraniliprole. On the other hand, additive or synergistic effects have been observed at high concentrations of NPV + biorational insecticides (Wakil et al. 2013). A possible reason for NPV-Ch synergism is that the selection pressure of insecticides makes them more vulnerable to viral occlusion bodies (OB). Exposure to chemical insecticide increases the developmental period, and this allows the viral infection to develop in the insect (Kumar et al. 2008). The antagonistic or additive interaction in the present study might be due to a decrease in normal feeding on treatment or a change of gut pH (El-Helaly and El-Bendary 2013). The results of the present study showed that the sub-lethal concentration of chlorantraniliprole + high concentration of NPV could be a better strategy to manage insecticidal resistance. 


\section{Conclusion}

The obtained data showed that the lethal concentration of NPV in combination with chlorantraniliprole caused high larval mortality rates of Spodoptera spp. under laboratory conditions and could be suggested as an effective strategy to control the population Spodoptera spp., but further experiments under field conditions would be very helpful for the integration of NPV biopesticides with insecticides in the IPM program.

\section{Abbreviations \\ NPV: Nucleopolyhedroviruses; dsDNA: Double-stranded deoxyribonucleic acid; GVs: Granuloviruses; SIM-NPV: Spodoptera litura multicapsid nuclear polyhedrosis virus; RH: Relative humidity; L:D: Light:dark; WN: Weight by volume; POB: Polyhedral occlusion body; CTF: Co-toxicity factor; Oc: Observed mortality; Oe: Expected mortality; HSD: Honestly significant difference}

\section{Acknowledgements}

The authors are highly thankful to Muhammad Umair Aslam and Rauf Ali, laboratory attendants of Entomological Research Institute, Faisalabad, Pakistan, for their untiring efforts in the specimen collection and maintenance of insect culture. The authors are also thankful to the anonymous reviewers for their constructive comments.

\section{Authors' contributions}

GS designed and supervised the overall research. NAM and MAA conducted the experiments. MRS contributed to the statistical analysis. MAM helped in the extraction of NPV. MF contributed to the data analysis and manuscript write-up. All authors have read and approved the final manuscript.

\section{Funding}

The Agriculture Department, Government of the Punjab, Pakistan, sponsored the studies.

\section{Availability of data and materials}

Data will be accessible on request from the corresponding authors.

\section{Declarations}

Ethics approval and consent to participate

Not applicable.

\section{Consent for publication}

Not applicable.

\section{Competing interests}

The authors declare that they have no competing interests.

\section{Author details}

${ }^{1}$ Cotton Research Station, Ayub Agricultural Research Institute, Faisalabad, Pakistan. ${ }^{2}$ Regional Agricultural Research Institute, Bahawalpur, Pakistan. ${ }^{3}$ Rice Research Station, Bahawalnagar, Pakistan. ${ }^{4}$ Department of Entomology, University of Agriculture, Faisalabad, Pakistan. ${ }^{5}$ School of Biology and Environmental Science, Faculty of Science, Queensland University of Technology, Brisbane, Australia.

Received: 17 December 2020 Accepted: 10 March 2021 Published online: 24 March 2021

\section{References}

Abbott WS (1925) A method of computing the effectiveness of an insecticide. J Econ Entomol 18(2):265-267. https://doi.org/10.1093/jee/18.2.265a

Ahmad JN, Mushtaq R, Ahmad SJN, Malik MA, Manzoor M, Tahir M, Aslam Z, Maqsood S, Ahuja I, Bones AM (2020) Sub-lethal dose reponses of native polyhydroviruses and spinosad for economical and sustainable management of Spodoptera litura in Pakistan. Pak J Zool 52(3):989-999
Ahmad JN, Mushtaq R, Ahmad SJN, Maqsood S, Ahuja I, Bones AM (2018) Molecular identification and pathological characteristics of NPV isolated from Spodoptera litura (Fabricius) in Pakistan. Pak J Zool 50(6):2229-2237

Ahmad M, Sayyed AH, Saleem MA, Ahmad M (2008) Evidence for field evolved resistance to newer insecticides in Spodoptera litura (Lepidoptera: Noctuidae) from Pakistan. Crop Protection 27(10):1367-1372. https://doi.org/10.1016/j. cropro.2008.05.003

Ali G, van der Werf W, Vlak JM (2018) Biological and genetic characterization of a Pakistani isolate of Spodoptera litura nucleopolyhedrovirus. Biocontrol Sci Technol 28(1):20-33. https://doi.org/10.1080/09583157.2017.1409339

Ayyub MB, Nawaz A, Arif MJ, Amrao L (2019) Individual and combined impact of nuclear polyhedrosis virus and spinosad to control the tropical armyworm, Spodoptera litura (Fabricius)(Lepidoptera: Noctuidae), in cotton in Pakistan. Egypt J Biol Pest Control 29(1):67. https://doi.org/10.1186/s41938-019-0170-4

Cordova D, Benner EA, Sacher MD, Rauh JJ, Sopa JS, Lahm GP, Selby TP, Stevenson TM, Flexner L, Gutteridge S, Rhoades DF, Wu L, Smith RM, Tao Y (2006) Anthranilic diamides: a new class of insecticides with a novel mode of action, ryanodine receptor activation. Pesticide Biochem Physiol 84(3):196214. https://doi.org/10.1016/j.pestbp.2005.07.005

Cordova D, Benner EA, Sacher MD, Rauh JJ, Sopa JS, Lahm GP, Selby TP, Stevenson TM, Flexner L, Gutteridge S, Rhoades DF (2007) The novel mode of action of anthranilic diamide insecticides: ryanodine receptor activation. In: Lyga JW, Theodoridis G (ed) Synthesis and Chemistry of Agrochemicals VII, p 223-34. https://doi.org/10.1021/bk-2007-0948.ch017

El-Helaly AA, El-Bendary HM (2013) Impact of Spinosad and nucleopolyhedrovirus alone and in combination against the cotton leaf worm Spodoptera littoralis under laboratory. Appl Sci Rep 2:17-21

Farahani S, Talebi AA, Fathipour Y (2012) Life table of Spodoptera exigua (Lepidoptera: Noctuidae) on five soybean cultivars. Psyche 2012:1-7. https:// doi.org/10.1155/2012/513824

Fu X, Feng H, Liu Z, Wu K (2017) Trans-regional migration of the beet armyworm, Spodoptera exigua (Lepidoptera: Noctuidae), in North-East Asia. Plos One 12(8):e0183582. https://doi.org/10.1371/journal.pone.0183582

Gothama AAA, Sikorowski PP, Lawrence GW (1995) Interactive effects of Steinernema carpocapsae and Spodoptera exigua nuclear polyhedrosis virus on Spodoptera exigua larvae. J Invert Pathol 66(3):270-276. https://doi.org/1 0.1006/jipa.1995.1100

Ishtiaq M, Saleem MA, Razaq M (2012) Monitoring of resistance in Spodoptera exigua (Lepidoptera: Noctuidae) from four districts of the Southern Punjab, Pakistan to four conventional and six new chemistry insecticides. Crop Prot 33:13-20. https://doi.org/10.1016/j.cropro.2011.11.014

Kumar M, Pradip KS, Anirudh KS (2012b) Studies on pheromone catches of Helicoverpa armigera hubner and relation of moth activity with larval infestation on tomato in Baghpat Uttar Pradesh. Int J Microbial Res Technol 2:1-3

Kumar NS, Murugan K, Zhang W (2008) Additive interaction of Helicoverpa armigera nucleopolyhedrovirus and azadirachtin. BioControl 53(6):869-880. https://doi.org/10.1007/s10526-007-9115-z

Kumar R, Chakravarty MK, Mondal P (2012a) Management of Helicoverpa armigera (Hübner) in chick pea by insecticides. Ann Plant Prot Sci 20(2):338-340

Laarif A, Salhi E, Fattouch S, Hammouda MHB (2011) Molecular detection and biological characterization of a nucleopolyhedrovirus isolate (Tun-SINPV) from Spodoptera littoralis in Tunisian tomato greenhouses. Ann Biol Res 2(4): 180-191

Lahm GP, Stevenson TM, Selby TP, Freudenberger JH, Cordova D, Flexner L, Bellin CA, Dubas CM, Smith BK, Hughes KA, Hollingshaus JG, Clark CE, Benner EA (2007) Rynaxypyr ${ }^{\mathrm{TM}}$ : a new insecticidal anthranilic diamide that acts as a potent and selective ryanodine receptor activator. Bioorg Med Chem Lett 17(22):6274-6279. https://doi.org/10.1016/j.bmcl.2007.09.012

Luna-Espino JC, Castrejón-Gómez VR, Pineda S, Figueroa JI, Martínez AM (2018) Effect of four multiple nucleopolyhedrovirus isolates on the larval mortality and development of Spodoptera exigua (Lepidoptera: Noctuidae): determination of virus production and mean time to death. Fla Entomol 101(2):153-159. https://doi.org/10.1653/024.101.0201

Ma X-M, Liu X-X, Ning X, Zhang B, Han F, Guan X-M, Tan YF, Zhang QW (2008) Effects of Bacillus thuringiensis toxin Cry1AC and Beauveria bassiana on Asiatic corn borer (Lepidoptera: Crambidae). J Invert Pathol 99(2):123-128. https:// doi.org/10.1016/j.jip.2008.06.014

Mansour NA, Eldefrawi ME, Toppozada A, Zeid M (1966) Toxicological studies on the Egyptian cotton leafworm, Prodenialitura VI potentiation and antagonism of carbamate insecticide. J Econ Entomol 59(2):307-311. https://doi.org/10.1 093/jee/59.2.307 
Nathan SS, Kalaivani K (2006) Combined effects of azadirachtin and nucleopolyhedrovirus (SpltNPV) on Spodoptera litura Fabricius (Lepidoptera: Noctuidae) larvae. Biol Control 39(1):96-104. https://doi.org/10.1016/j. biocontrol.2006.06.013

Rios-Velasco C, Gallegos-Morales G, Rincón-Castro MCD, Cerna-Chávez E, Sánchez-Peña SR, Siller MC (2011) Insecticidal activity of native isolates of Spodoptera frugiperda multiple nucleopolyhedrovirus from soil samples in Mexico. Fla Entomol 94(3):716-718. https://doi.org/10.1653/024.094.0346

Sayyed AH, Naveed M, Rafique M, Arif MJ (2012) Detection of insecticides resistance in Spodoptera exigua (Lepidoptera: Noctuidae) depends upon insect collection methods. Pak Entomol 34:7-15

Shapiro A, Green T, Rao S, White S, Carner G, Mertens PPC, Becnel JJ (2005) Morphological and molecular characterization of a cypovirus (Reoviridae) from the mosquito Uranotaenia sapphirina (Diptera: Culicidae). J Virol 79(15): 9430-9438. https://doi.org/10.1128/JVI.79.15.9430-9438.2005

Sokal R, Rohlf F (1995) Biometry, 3rd editon. Freeman, New York

Sosa-Gómez DR (2017) Microbial control of soybean pest insects and mites. In: Lacey L (ed) Microbial Control of Insect and Mite Pests. Academic Press, p. 199-208.

Wakil W, Ghazanfar MU, Nasir F, Qayyum MA, Tahir M (2012) Insecticidal efficacy of Azadirachta indica, nucleopolyhedrovirus and chlorantraniliprole singly or combined against field populations fo Helicoverpa armigera Hübner (Lepidoptera: Noctuidae). Chilean J Agric Res 72(1):53-61.

Wakil W, Ghazanfar MU, Riasat T, Qayyum MA, Ahmed S, Yasin M (2013) Effects of interactions among Metarhizium anisopliae, Bacillus thuringiensis and chlorantraniliprole on the mortality and pupation of six geographically distinct Helicoverpa armigera field populations. Phytoparasitica 41(2):221-234. https://doi.org/10.1007/s12600-012-0282-9

Wang D, Wang Y-M, Liu H-Y, Xin Z, Xue M (2013) Lethal and sublethal effects of spinosad on Spodoptera exigua (Lepidoptera: Noctuidae). J Econ Entomol 106(4):1825-1831. https://doi.org/10.1603/EC12220

Williams T, Virto C, Murillo R, Caballero P (2017) Covert infection of insects by baculoviruses. Front Microbiol 8:1337. https://doi.org/10.3389/fmicb.2 017.01337

Wilson K, Cotter SC, Reeson AF, Pell JK (2001) Melanism and disease resistance in insects. Ecol Lett 4(6):637-649. https://doi.org/10.1046/j.14 61-0248.2001.00279.x

\section{Publisher's Note}

Springer Nature remains neutral with regard to jurisdictional claims in published maps and institutional affiliations.

\section{Submit your manuscript to a SpringerOpen ${ }^{\circ}$ journal and benefit from:}

- Convenient online submission

- Rigorous peer review

- Open access: articles freely available online

- High visibility within the field

- Retaining the copyright to your article

Submit your next manuscript at $\boldsymbol{\nabla}$ springeropen.com 